\title{
Same-different judgments under high speed stress: Missing-feature principle predominates in early processing
}

\author{
LESTER E. KRUEGER and MARK H. CHIGNELL \\ Ohio State University, Columbus, Ohio
}

\begin{abstract}
Three well-practiced subjects made same-different judgments of letter pairs under varying degrees of speed stress. In contrast to the preponderance of false-different errors found using the same method without speed stress (Chignell \& Krueger), there were more false-same responses, particularly on similar different pairs. The early, or developing, percept looks very similar from one letter to another, apparently because real differences between letters frequently are missed, whereas spurious differences due to missing or unresolved features at encoding or comparison are simply disregarded (missing-feature principle) rather than interpreted as featural mismatches (internal-noise principle). Distinguishing features are added quite late $(300+\mathrm{msec})$ in processing, just as Eriksen, O'Hara, and Eriksen proposed.
\end{abstract}

Studies of same-different judgments of letter pairs typically have focused on reaction time $(\mathrm{RT})$ rather than errors, and in particular on why same judgments are faster than different judgments (Krueger, 1978; Nickerson, 1978; Proctor, 1981). Errors may be equally as important as RT, however, and may even provide the basis for an explanation of the fast-same effect. According to the noisy-operator theory (Krueger, 1978), false-different errors (i.e., on same pairs) typically exceed false-same ones because internal noise more often changes physical matches into spurious perceived mismatches than vice versa. As a result, different judgments are slower, because of the rechecking done to eliminate the spurious mismatches.

In previous studies, errors increased more on same than on different trials under difficult conditions (Carr, Posner, Pollatsek, \& Snyder, 1979; Krueger, 1985; Krueger \& Gott, 1985; Krueger \& Shapiro, 1985), as predicted by the internal-noise principle. However, task difficulty was increased in these studies by altering stimulus characteristics rather than by limiting the amount of processing time permitted. If information accrues continuously (Eriksen \& Schultz, 1979; McClelland, 1979; Ratcliff, 1981, 1985), then meaningful, but less accurate (i.e., noisier), responses may be obtained before the percept has fully developed. The present study tested whether high speed stress would increase mainly false-different errors or

This study was supported by a postdoctoral fellowship to Mark H. Chignell from the Graduate School, Ohio State University. The authors are grateful to Mary Pejeau for assistance in obtaining the data. Mark H. Chignell is now at the Department of Industrial and Systems Engineering, University of Southern California, Los Angeles, CA 900891452. Requests for reprints should be sent to Lester E. Krueger, Human Performance Center, Ohio State University, 404-B West 17th Avenue, Columbus, $\mathrm{OH} 43210$. mainly false-same errors. According to the internal-noise principle, subjects under high speed stress would have little time to recheck and remove spurious mismatches, so false-different errors should predominate. According to the missing-feature principle, however, subjects under high speed stress frequently would fail to detect true featural mismatches because the differing features would be missing or obscured for both letters at encoding or comparison, and they would disregard mismatches arising when a feature was missing or obscured for one letter but not for the other. Consequently, false-same errors should predominate.

\section{Missing-Feature Principle}

Some evidence suggests that letters tend to look very much alike early in processing, as predicted by the missing-feature principle. Lockhead (1972) proposed that every stimulus was initially processed holistically, as a blob, with the attributes of the stimulus being further analyzed and processed separably only if the task required it (see also Navon, 1977). Eriksen, O'Hara, and Eriksen (1982) said that different stimuli would often share many features, particularly at the early levels of percept development, and "on the average, the percept will need to develop rather fully before a difference is detected" (p. 263). According to their response-competition model, subjects take into account perceived sameness and difference, not just perceived difference (Krueger, 1978), and matching features on similar different pairs produce a response tendency towards "same." Eriksen et al. obtained nearly as many false-same errors $(5.6 \%)$, which they attributed to the missing-feature factor, as falsedifferent errors $(7.8 \%)$, which they attributed to the internal-noise principle. They said that "errors on different trials occur when the subject's criterion is set so low that a same judgment is made before the percept has devel- 
oped enough to permit discrimination or detection of all the relevant characteristics of the stimuli" (p. 263).

In early processing, the absence of a feature may simply be taken to indicate a delay in its arrival, and it generally has been assumed that observers tolerate missing features but not added inappropriate features when making tachistoscopic letter identifications (Broadbent, 1967; Lindsay \& Norman, 1977; Rumelhart \& Siple, 1974). Shapiro and Krueger (1983) found that adding an inappropriate feature made a letter look more illegal than did deleting a feature.

Proctor and Rao (1983b) questioned the assumption of the noisy-operator theory that internal noise "mainly serves to perturb rather than delete features"' (Krueger, 1978, p. 281), citing evidence that feature deletion is more likely than feature addition. However, the tendency for feature deletion to predominate may be much greater under high speed stress and on data-limited, tachistoscopic tasks in which the stimuli are degraded (Proctor \& Rao, 1983b; Shapiro \& Krueger, 1983) than on normal matching tasks (Krueger \& Shapiro, 1985). Furthermore, even if deletion generally exceeded addition, spurious mismatches would still be more likely to occur than spurious matches, since the deletion as well as the addition of a feature in one, but not the other, of two matching stimuli should produce a perceived mismatch. Simulations by the first author with a modified model (similar to one used by Krueger \& Shapiro, 1985) indicated that the fast-same effect would be predicted even if deletion exceeded addition.

Deletions would pose a problem for the internal-noise principle only if the spurious mismatches they produced were disregarded, which remains a possibility only in early processing, and will be tested here. The present experimental procedure, when used without high speed stress, produced a preponderance of false-different errors (Chignell \& Krueger, 1984), so with high speed stress it should be sensitive to any shift towards false-same errors in early processing, as predicted by the missingfeature principle.

Proctor and Rao (1983a) found a preponderance of false-different errors in one case, but said that they had not consistently obtained such an effect. Greater speed stress in their laboratory, which would tend to produce more false-same errors according to the missing-feature principle, might explain their failure to find a consistent error effect. In our own laboratory, we not only ask subjects to make as few errors as possible, but routinely discard the data from those whose errors exceed $8 \%$. As a result, we have consistently found a preponderance of false-different errors (e.g., Chignell \& Krueger, 1984), as predicted by the internal-noise principle.

\section{Variation of Speed Stress}

To examine the error tendencies in early processing, subjects in the present experiment were placed under varying degrees of speed stress. Snodgrass, Luce, and Galanter
(1967) found that subjects could accurately time simple reactions to fall within 20-msec-wide time bands or windows, and their method was used here. On each block of trials, a response that failed to fall within a particular 50-msec range, or window, received corrective feedback ("too slow" or "fast" message). The present task is difficult and demanding, and it requires much practice. Krueger and Shapiro (1981, Experiment IV) found a significant increase in errors, but not in speed, when they asked 10 unpracticed subjects to make their same-different judgments "as quickly as you can, even if that means making many errors." In order to obtain a significant increase in speed, we decided to run ourselves repeatedly, along with an undergraduate assistant who did not know the purpose or background of the experiment.

There are two basic theories (all-or-none; incremental) of how speed is traded for accuracy (Pachella, 1974; Wickelgren, 1977). The all-or-none theory (Ollman, 1966; Swensson, 1972) depicts the subject as being in one of only two states or modes when responding: (1) normal processing is completed (stimulus-controlled response), or (2) it is not (fast guess). The incremental theory (Fitts, 1966) permits many intermediate modes as well, so that a decision may be based on partial information. We assumed that the incremental theory was basically true, and that subjects would revert to fast guesses only under the most extreme speed stress.

The present study used virtually the same method (brief, simultaneous presentation; the same set of six letters) as Chignell and Krueger (1984), but introduced high speed stress. Half of the different pairs contained two similar letters and half contained two dissimilar letters. Chignell and Krueger found that RT was lower on same than on different pairs, and that false-different errors on same pairs consistently exceeded even false-same errors on similar different pairs. If the missing-feature principle supercedes the internal-noise principle in early processing, however, then false-same rather than false-different errors ought to predominate in the present study.

\section{METHOD}

\section{Subjects}

The three subjects were an undergraduate assistant (M.P.), who was not told the purpose of the study, and the two authors of this report, who knew the purpose of the study but did not discuss their specific experiences during the several weeks they served as subjects. Each subject had one practice session, followed by 12 regular sessions.

\section{Apparatus}

Uppercase letters were presented at a $60-\mathrm{Hz}$ refresh rate and at $32 \mathrm{~cd} / \mathrm{m}^{2}$ intensity on a greenish-tint, fast-decay P31 phosphor (decay to $1 \%$ intensity at $.25 \mathrm{msec}$ after display offset) by an Imlac PDS-4 graphics computer, which also measured RT to an accuracy of $1 \mathrm{msec}$. The letters, presented as thin, illuminated lines on a dark screen, were software generated, using short line vectors, so as to resemble normal English uppercase letters. Each subject sat alone in a dark room, with the head held fast in a chinrest located $70 \mathrm{~cm}$ from the display screen. 


\section{Stimulus Materials}

Each letter was $0.29 \mathrm{~cm}$ wide and $0.43 \mathrm{~cm}$ high, and $0.19 \mathrm{~cm}$ separated the two letters. The pair thus was $0.77 \mathrm{~cm}\left(0.63^{\circ}\right)$ wide. The two letters were centered $0.3 \mathrm{~mm}$ above a small $(1.6 \times 1.6 \mathrm{~mm})$ plus sign, which was the fixation mark at the center of the screen.

Six letters (D, H, M, O, V, Y) were used to form 6 same pairs and 12 different pairs, 6 of which were similar (DO, OD, HM, MH, VY, YV) and 6 dissimilar (DY, YD, HV, VH, MO, OM). Half of the pairs presented in each condition were same and half were different. Each same pair was presented 12 times and each different pair 6 times within each speed-stress condition, or 144 regular trials in all. The 144 trials were divided into six blocks (each preceded by 3 practice trials) of 24 regular trials each, and a 27 trial practice block began the speed-stress condition. Each subject received all four speed-stress conditions (a total of 576 regular trials) in each session. Four different random sequences of trials and letter pairs were prepared, and each subject cycled through the set of four randomizations three times in completing 12 regular sessions.

\section{Procedure}

Subjects M.C. and M.P. responses "same" with the right hand and "different" with the left hand, whereas Subject L.K. had the reverse hand assignment. On each trial, the fixation mark appeared alone for $.5 \mathrm{sec}$, was accompanied by the target pair for $.2 \mathrm{sec}$, and then appeared alone again until the subject responded. A 1-sec feedback message indicated whether the RT fell below (FAST), within (no message on screen), or above (TOO SLOW) the required $\mathrm{RT}$ range. There was a 5-sec interval between blocks, which allowed the next set of 27 trials to be read in from the host computer.

Prior to each new speed-stress condition, a 5-sec message instructed the subject to INCREASE (DECREASE) YOUR SPEED BY 50 MSEC if the RT range successively decreased (increased) in that session. The RT range successively decreased on the 6 oddnumbered sessions and successively increased on the 6 evennumbered sessions. The same RT ranges were used in all $12 \mathrm{regu}-$ lar sessions for a particular subject.

In the initial, practice session, no feedback on speed was given, and the subject responded at a rapid normal rate, which was used to set the slowest rate (highest RT range) in the 12 regular sessions. Mean RT in the practice session was 415,516 , and $558 \mathrm{msec}$, respectively, for Subjects M.C., M.P., and L.K., whereas errors were $5.90 \%, 3.47 \%$, and $2.43 \%$, respectively. The four target RT ranges for Subject M.C. were 200-250, 250-300, 300-350, and 350$400 \mathrm{msec}$; those for Subjects M.P. and L.K. were set 100 and $150 \mathrm{msec}$ higher, respectively (see Table 1).

Except as otherwise stated (see Figure 1), RT was computed for correct trials only. After each session, personal experiences and observations on the session were recorded by the subject.

\section{RESULTS}

As shown in Table 1, RT significantly increased as the target $R T$ range increased $[F(3,6)=39.31, p<.001]$, whereas errors decreased $[F(3,6)=33.91, p<.001]$. Same judgments were faster than different judgments [ 383 vs. $397 \mathrm{msec} ; \mathrm{F}(1,2)=18.11, \mathrm{p} \approx .051$, but less errorful $[18.42 \%$ vs. $28.63 \% ; F(1,2)=4.05$, n.s.]. Subjects M.C. and L.K. each made more false-same than falsedifferent responses in all 12 of their sessions; Subject M.P. did so in 5 of the 12 sessions.

The practice session enabled each subject to become fully attuned to the comparison task. There was no tendency for speed or accuracy to improve across the 12 regular sessions. Judgments were somewhat, but not significantly, slower $[15 \mathrm{msec} ; \mathrm{F}(1,2)=12.10, \mathrm{p}<.10]$ and more accurate $[2.66 \% ; F(1,2)=2.85$, n.s. $]$ in ses-
Table 1

Mean Response Time (RT; in Milliseconds) and Percentage of Error Rate (PE) by Trial Type and Target RT Ranges (in Milliseconds) per Subject

\begin{tabular}{|c|c|c|c|c|c|c|}
\hline \multirow{3}{*}{$\begin{array}{c}\text { Target RT } \\
\text { Range }\end{array}$} & \multicolumn{6}{|c|}{ Trial Type } \\
\hline & \multicolumn{2}{|c|}{ Same } & \multicolumn{2}{|c|}{$\begin{array}{c}\text { Similar } \\
\text { Different }\end{array}$} & \multicolumn{2}{|c|}{$\begin{array}{l}\text { Dissimilar } \\
\text { Different }\end{array}$} \\
\hline & RT & PE & RT & PE & RT & PE \\
\hline \multicolumn{7}{|c|}{ Subject M.C. } \\
\hline $200-250$ & 239 & 31.60 & 239 & 66.44 & 245 & 56.48 \\
\hline $250-300$ & 282 & 28.70 & 298 & 57.64 & 306 & 36.34 \\
\hline $300-350$ & 322 & 21.18 & 345 & 50.23 & 344 & 23.61 \\
\hline $350-400$ & 338 & 16.32 & 386 & 43.12 & 355 & 8.58 \\
\hline \multicolumn{7}{|c|}{ Subject M.P. } \\
\hline $300-350$ & 379 & 33.36 & 408 & 38.99 & 379 & 21.53 \\
\hline $350-400$ & 411 & 25.23 & 422 & 38.43 & 412 & 20.29 \\
\hline $400-450$ & 449 & 19.10 & 481 & 32.24 & 446 & 11.17 \\
\hline $450-500$ & 474 & 16.60 & 515 & 22.24 & 472 & 10.80 \\
\hline \multicolumn{7}{|c|}{ Subject L.K. } \\
\hline $350-400$ & 391 & 10.67 & 412 & 53.70 & 378 & 7.18 \\
\hline $400-450$ & 413 & 8.22 & 460 & 44.44 & 395 & 3.24 \\
\hline $450-500$ & 428 & 6.60 & 473 & 29.39 & 411 & 1.16 \\
\hline $500-550$ & 468 & 3.47 & 508 & 9.72 & 431 & 0.23 \\
\hline
\end{tabular}

sions in which the target RT range successively decreased rather than increased, which suggests that when subjects started at a slower (faster) rate, they tended to retain the slower (faster) speed during the session. As shown in Table 1, though, mean RT for a given type of judgment generally was kept within the target $\mathrm{RT}$ range. The most common deviation was for mean RT to exceed the target range, indicating some resistance to the speed stress imposed. (Snodgrass, Luce, \& Galanter, 1967, Experiment III, likewise encountered resistance to a fast RT band on recognition and choice judgments.) Mean RT changed by 30 to $35 \mathrm{msec}$, on the average, between successive 50msec target RT ranges. Individual RT values fell within the target range on $36 \%, 24 \%$, and $25 \%$ of the trials, respectively, for Subjects M.C., M.P., and L.K.

Given the speed stress, and the imposition of a common, 50-msec target range for both trial types (same, different), mean RT differed rather little by trial type for a given RT range, whereas errors generally differed considerably (see Table 1). Each subject showed a different error pattern. For Subject M.P., errors increased about equally for all trial types, as speed stress increased, whereas for Subject M.C. the most dramatic increase in errors was on dissimilar different pairs, and for Subject L.K. it was on similar different pairs. These differences may simply reflect the fact that the three subjects were operating at different levels of the speed-accuracy tradeoff (e.g., Subject M.C. was generally faster, but less accurate, than Subject L.K.), which also varied somewhat for each subject within a particular block of trials. To eliminate the effect of such variation, each subject's responses, both correct and incorrect, as well as those for the group as a whole, were partitioned by RT interval. Each interval was $50 \mathrm{msec}$ wide (e.g., all RTs falling between 476 and $525 \mathrm{msec}$ were tallied as $500 \mathrm{msec}$ ). 


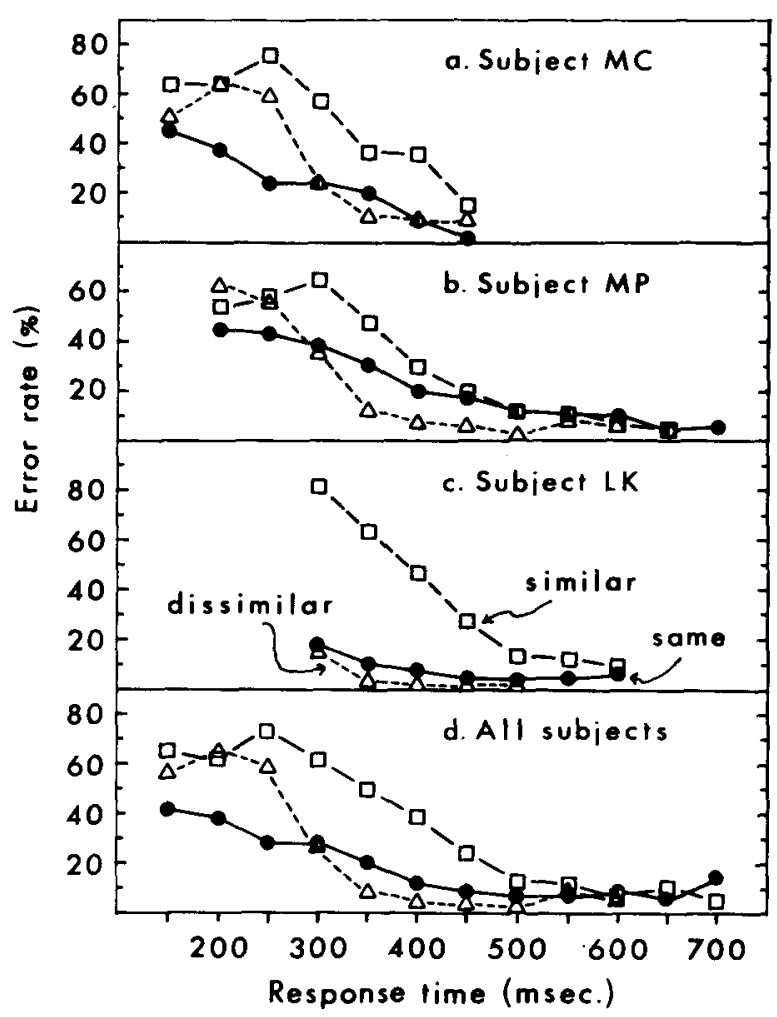

Figure 1. Percentage of errors by RT interval and trial type for each subject and the three subjects combined. If the interval contained fewer than $\mathbf{3 0}$ trials, the data point is not shown.

Figure 1 shows the error rate at each interval for each trial type. To eliminate unreliable data, only points based on at least 30 responses were plotted in Figure 1. The data at each interval were combined rather than shown separately for the four target ranges, because the error rate for a particular RT interval was largely independent of target range. There was only a slight and irregular tendency for errors to increase in a given RT interval as speed stress increased. Schouten and Bekker (1967) likewise found that responses within a particular time band had the same accuracy level regardless of whether they were fast reactions in a generally slow set of responses or slow reactions in a generally fast set of responses. Wickelgren (1977) said that "whenever this result is obtained, the partitioning method is an unbiased way to obtain a speedaccuracy tradeoff function" (p. 77).

Figure 1 shows a quite similar pattern of results for the three subjects. When RT is $500 \mathrm{msec}$ or above, errors differ relatively little, if at all, for the three trial types. As RT decreases to $350 \mathrm{msec}$, errors rise steeply for similar different pairs, somewhat for same pairs, and almost not at all for dissimilar different pairs. Below $350 \mathrm{msec}$, however, errors rise steeply for dissimilar different pairs. At $300 \mathrm{msec}$, all three subjects showed the same error rate on same and dissimilar different pairs, and a much higher error rate on similar different pairs. Thus, at
$300 \mathrm{msec}$, all subjects made many more false-same than false-different errors. Below $300 \mathrm{msec}$, one of the subjects dropped out, and for the two remaining subjects there are more errors on both types of different pairs, similar and dissimilar, than on same pairs.

When RT had decreased to 150 or $200 \mathrm{msec}$, performance was about at the chance level $(50 \%)$ and all error functions tended to converge towards the $50 \%$ rate, representing an equal tendency to guess "same" and "different." However, subjects apparently were not making only fast guesses, because errors were $40 \%$ on same trials and $60 \%$ on different trials for both Subject M.C. and Subject M.P. (see Figure 1). Swensson (1972) found a "dead time" of 80 to $100 \mathrm{msec}$ between the detection time and the time that performance exceeded chance accuracy in a discrimination task. The dead time was somewhat longer in the present case, extending approximately from an RT of $150 \mathrm{msec}$ to one of $300 \mathrm{msec}$ (see Figure 1). Another $200 \mathrm{msec}$ was required (i.e., an RT of $500 \mathrm{msec}$ ) for errors to decrease to their lower asymptote.

In their recorded observations, Subjects M.C. and L.K. noted how difficult it was to maintain proper accommodation and convergence during the entire session. Subject L.K. sometimes let his eyes become unfocused in order not to be distracted (and thus slowed down) by details. For him, too, the easiest way to reduce RT to the required range was to respond "same" immediately to highly similar pairs, without checking further for a difference. The latter two observations by Subject L.K. support the view (Eriksen et al. 1982; Lockhead, 1972) that specific details and differences are resolved relatively late in processing. Subjects M.C. and L.K. often set themselves to respond "same" unless a clear difference was detected. The readiness for a particular buttonpress was so high in some cases that an error was made "because the response just got out of me." Subjects M.C. and L.K. reported that they sometimes verbalized the letter pair on slow blocks in order to ensure that it received the full processing duration specified.

\section{DISCUSSION}

The present results contrast sharply with those of Chignell and Krueger (1984), who used nearly the same method (brief, simultaneous presentation; the same set of six letters), but without high speed stress. Their subjects, who were instructed to respond as rapidly as possible but not at the expense of accuracy, had a mean RT of about $625 \mathrm{msec}$ for both same and dissimilar different pairs, and one of about $650 \mathrm{msec}$ for similar different pairs. These values are nearly double the present $\mathrm{RT}$ values (see Table 1). An even greater change occurred on errors. Chignell and Krueger found only about 3\% errors, with errors on same pairs always exceeding (by about $1 \%$ or more) those on either similar or dissimilar different pairs. In the present study, by contrast, errors were highest on 
similar different pairs once RT fell below $500 \mathrm{msec}$, and even dissimilar different pairs had more errors than same pairs once RT fell below $300 \mathrm{msec}$. Thus, the usual effect of internal noise (i.e., preponderance of false-different responses) was not found in the present case.

The fact that the usual error effect was not merely eliminated, but reversed, indicates that the internal-noise principle was replaced or superceded by another principle. Different pairs were similar or dissimilar, and this heterogeneity of difference or external noise would tend to produce faster, but less accurate, judgments on different pairs (Krueger, 1978, 1979). Similar different pairs would tend to produce false-same errors, and the rechecking needed to eliminate such errors would slow down the same judgments. However, although errors were indeed higher on different pairs in the present study, the speed advantage for same pairs, which typically is about $20 \mathrm{msec}$ with simultaneous presentation, remained a quite respectable $14 \mathrm{msec}$. Thus, the RT data rule out external noise as the predominant factor in the present study.

More consistent with the error and RT pattern is the missing-feature principle and Eriksen et al.'s (1982) response-competition model. Matching features on similar different pairs would increase the perceived sameness count, and thus tend to slow the "different" response and produce many false-same errors. Early in processing, with many features missing and disregarded, even dissimilar different pairs might tend to look much alike, which may be why errors on those pairs exceeded errors on same pairs below $300 \mathrm{msec}$ (see Figure 1). The external-noise principle, by contrast, would predict higher errors on same (vs. dissimilar different) pairs, due to their confusion with similar different pairs, at all RT ranges.

Given the 14-msec fast-same effect, the preponderance of false-same errors might simply reflect a motor bias towards the "same" button. However, there is no reason to expect the motor bias to change under speed stress in the same manner for all three subjects and in precisely the pattern found here. Furthermore, a motor bias towards "same" should increase errors on both similar and dissimilar different pairs. For all three subjects, however, errors on similar different pairs rose steeply below $450 \mathrm{msec}$, but errors on dissimilar different trials lagged behind those on same trials above $300 \mathrm{msec}$, and exceeded errors on same trials only below $300 \mathrm{msec}$. Below $250 \mathrm{msec}$, all error functions tended to converge towards the $50 \%$ rate, representing an equal (nonbiased) tendency to guess "same" and "different."

There is one way, however, that a response bias towards "same" might have arisen at the faster RT ranges. Response bias can be induced by varying the proportion or relative frequency of same versus different trials (Proctor \& Rao, 1983a; Ratcliff, 1985). Nominally, same and different pairs were equally frequent in the present study, but functionally, many more same than different pairs may have been perceived, due to the missing-feature principle, as speed stress increased. This may explain why Subjects M.C. and L.K. often set themselves to respond "same" unless a clear difference was detected. However, it should be emphasized that any such bias towards "same" would be secondary to, and dependent upon, the missing-feature principle, whose error and RT pattern it merely accentuated. Furthermore, it is likely that the response bias was quite modest. In detection tasks, subjects typically are conservative and resist changing the criterion fully when relative frequency or payoffs are changed (Green \& Swets, 1966). In the same-different judgment task, likewise, criterion stability (even when inappropriate) is more the norm than is criterion shifting (Krueger, 1985).

In sum, the present results show that speed stress is a potent factor in perceptual matching. Variations in the same-different error disparity obtained by different experimenters may be attributable in part to differences in the amount of speed stress. Failure to consider the effects of varying levels of speed stress thus may have obscured the important role of errors as indicators of underlying factors or processes in perceptual matching (Proctor \& Rao, 1983a). It is likely that the predominance of falsesame errors with high speed stress and false-different errors with low speed stress (Chignell \& Krueger, 1984) is due to the changing locus and nature of processing difficulty as evidence about the stimulus pair accumulates. In the early (first $300 \mathrm{msec}$ ) stages of processing, apparent sameness of different pairs is caused by the failure to detect or properly compare differentiating features, and the unwillingness of subjects to take seriously those spurious mismatches which involve a missing or unresolved feature at encoding or comparison (Eriksen et al., 1982). Matching at later stages of processing appears to involve a qualitatively different process, with false-different errors predominating as the addition of partially resolved or possibly perturbed features increases the likelihood that same pairs will be misperceived as different.

\section{REFERENCES}

Broadbent, D. E. (1967). Word-frequency effect and response bias. Psychological Review, 74, 1-15.

Carr, T. H., Posner, M. I., Pollatsek, A., \& Snyder, C. R. R. (1979). Orthography and familiarity effects in word processing. Journal of Experimental Psychology: General, 108, 389-414.

Chignell, M. H., Krugger, L. A. (1984). Further evidence for priming in perceptual matching: Temporal, not spatial, separation enhances the fast-same effect. Perception \& Psychophysics, 36, 257-265.

ErIKSEn, C. W., O'Hara, W. P., \& ErIKSEN, B. A. (1982). Response competition effects in same-different judgments. Perception \& Psychophysics, 32, 261-270.

ERIKSEN, C. W., \& Schultz, D. W. (1979). Information processing in visual search: A continuous flow conception and experimental results. Perception \& Psychophysics, 25, 249-263.

FirTs, P. M. (1966). Cognitive aspects of information processing: III Set for speed versus accuracy. Journal of Experimental Psychology, 71, 849-857.

Green, D. M., SWETS, J. A. (1966). Signal detection theory and psychophysics. New York: Wiley.

KRUEger, L. E. (1978). A theory of perceptual matching. Psychological Review, 85, 278-304.

Krueger, L. E. (1979). A model of unidimensional perceptual matching. Journal of Experimental Psychology: Human Perception and Performance, 5, 277-288.

KRUEGER, L. E. (1985). Effect of intermixed foveal and parafoveal 
presentation on same-different judgments: Evidence for a criterioninertia model. Perception \& Psychophysics, 37, 266-271.

KRUEGER, L. E., \& GoTT, R. E. (1985). Effect of lateral masking and letter reversal on same-different judgments. Bulletin of the Psychonomic Society, 23, 185-188.

KRUEGer, L. E., \& SHAPIRo, R. G. (1981). Intertrial effects of samedifferent judgements. Quarterly Journal of Experimental Psychology, 33A, 241-265.

Krueger, L. E., \& Shapiro, R. G. (1985). Effect of interstimulus interval and heterogeneity of difference on same-different judgments of visual patterns. Bulletin of the Psychonomic Society, 23, 43-46.

Lindsay, P. H., \& NoRMAN, D. A. (1977). Human information processing: An introduction to psychology (2nd ed.). New York: Academic Press.

Lockhead, G. R. (1972). Processing dimensional stimuli: A note. Psychological Review, 79, 410-419.

MCCLELLAND, J. L. (1979). On the time relations of mental processes: An examination of systems of processes in cascade. Psychological Review, 86, 287-330.

Navon, D. (1977). Forest before trees: The precedence of global features in visual perception. Cognitive Psychology, 9, 353-383.

Nickerson, R. S. (1978). On the time it takes to tell things apart. In J. Requin (Ed.), Attention and performance VII (pp. 77-88). Hillsdale, NJ: Erlbaum.

Ollman, R. T. (1966). Fast guesses in choice reaction time. Psychonomic Science, 6, 155-156.

Pachella, R. G. (1974). The interpretation of reaction time in information-processing research. In B. H. Kantowitz (Ed.), Human information processing: Tutorials in performance and cognition (pp. 41-82). Hillsdale, NJ: Erlbaum.

Proctor, R. W. (1981). A unified theory for matching-task phenomena. Psychological Review, 88, 291-326.
Proctor, R. W., \& Rao, K. V. (1983a). Evidence that the same-different disparity in letter matching is not attributable to response bias. Perception \& Psychophysics, 34, 72-76.

Proctor, R. W., \& RAO, K. V. (1983b). Reinstating the original principles of Proctor's unified theory for matching-task phenomena: An evaluation of Krueger and Shapiro's reformulation. Psychological Review, 90, 21-37.

RATCLIFF, R. (1981). A theory of order relations in perceptual matching. Psychological Review, 88, 552-572.

RATCLIF, R. (1985). Theoretical interpretations of the speed and accuracy of positive and negative responses. Psychological Review, 92 , 212-225.

Rumelhart, D. E., \& SiPle, P. (1974). Process of recognizing tachistoscopically presented words. Psychological Review, 81, 99-113.

Schouten, J. F., \& BeKKer, J. A. M. (1967). Reaction time and accuracy. Acta Psychologica, 27, 143-153.

Shapiro, R. G., \& KrUeger, L. E. (1983). Effect of similarity of surround on target-letter processing. Journal of Experimental Psychology: Human Perception and Performance, 9, 547-559.

Snodgrass, J. G., Luce, R. D., \& Galanter, E. (1967). Some experiments on simple and choice reaction time. Journal of Experimental Psychology, 75, 1-17.

SwEnsson, R. G. (1972). The elusive tradeoff: Speed versus accuracy in visual discrimination tasks. Perception \& Psychophysics, 12, 16-32.

WICKELGREN, W. A. (1977). Speed-accuracy tradeoff and information processing dynamics. Acta Psychologica, 41, 67-85.

(Manuscript received May 3, 1985; revision accepted for publication July 24,1985 .) 